\title{
The Effect of Biofeedback Therapy on Hand Function and Daily Activities in Stroke Survivors
}

\author{
Tahereh Haji-Ahmad, ${ }^{1}$ Hojjat Allah Haghgoo, ${ }^{1, *}$ Ebrahim Pishyareh, and Akbar Biglarian ${ }^{2}$ \\ ${ }^{1}$ Department of Occupational Therapy, University of Social Welfare and Rehabilitation Sciences, Tehran, IR Iran \\ ${ }^{2}$ Department of Biostatistics, University of Social Welfare and Rehabilitation Sciences, Tehran, IR Iran \\ *Corresponding author: Hojjat Allah Haghgoo, Department of Occupational Therapy, University of Social Welfare and Rehabilitation Sciences, Tehran, IR Iran. E-mail: h.haghgoo@uswr.ac.ir \\ Received 2013 July 24; Accepted 2013 August 21.
}

\begin{abstract}
Background: Due to progressive increase in stroke incidence and need for effective therapy, the effectiveness of biofeedback therapy on the hand function and activities of daily living performances in stroke survivors were studied.

Patients and Methods: In this randomized control trial study, 24 participants(mean age 54.75 years)were divided randomly in experiment and control groups. Their affected hands were evaluated before and after intervention using Barthel index questionnaire, Ashworth test and goniometry in elbow, wrist and finger. The two groups received current occupational therapy intervention for 3 months, 3 sessions (each session was 45 minutes) in a week. The experimental group also had 15 minute biofeedback therapy in each session.

Results: Biofeedback trained group showed more decrease in spasticity, significants increase in range of motion in elbow $(\mathrm{P}<0.001)$, wrist $(\mathrm{P}<0.003)$ and finger $(\mathrm{P}<0.001)$ and significant increase in activities of daily living performances $(\mathrm{P}<0.001)$.

Conclusions: Biofeedback in accompanying with routine occupational therapy promised to be more effective in stroke survivors.
\end{abstract}

Keywords: Activities of daily living, Biofeedback, Stroke, Range of motion

\section{Background}

Stroke as the most common brain disorders is the third cause of death $[1,2]$ and its consequences continued more than 24 hours [3]. The rate of stroke incidence is about 3 in 100,000 in 3 rd and 4 th decade of age which increases to 300 in 100,000 people during 8 th and 9th decades [4]. Long lasting and disabling consequences mark stroke as the third cause of death due to disease in the world [2]. The most common stroke related disorders are manifested as hemiplegia, imbalance, incoordination and spasticity which are especially seen in upper extremities [5]. Motor and psychomotor disorders lead to limb inactivation, additional paralysis and palsy, problems in activities of daily living performance, problems in personal activity and social participation and finally more dependency and decrease in quality of life [6]. Lots of treatment procedures are available to deal with these problems, such as early medical interventions and rehabilitation programs and a wide range of techniques and approaches are used currently in rehabilitation programs [7].

These techniques have partial effectiveness especially for upper extremities and hand as key role player in activities of daily living (ADL) performances. On the other hand recovery should occur up to 11th week after stroke incidence, because after that period the expectation of recovery is very low [8]. Regarding these facts, it is necessary to develop therapeutic techniques or combine different techniques to improve and accelerate recovery of upper extremity in stroke survivors [7].

As an effective intervention in this field, using electromyographic biofeedback, help the patients to control motor activities $[9,10]$. Using biofeedback in accompanying with traditional interventions have been studied in some experiments and has showed its effectiveness in improving function in gross muscles (shoulder muscles or legs) [11]. While these studies have focused on recovery of gross muscles [12-15], fine movements of hand which are very critical in activities of daily living are ignored. Only in one research, the effectiveness of biofeedback therapy on the spasticity in wrist flexors, upper extremity function and ADL performances has been studied in the patients with stroke [16].

The results indicated improvements in reducing spasticity, upper extremity function, and increase in joints range of motion [16]. However there are not enough convincing evidences to support the effectiveness of biofeedback while there are some controversial reports [17-19]. Furthermore, it is not clear whether these functional improvements, can lead to better activities of daily living performances?

\section{Objectives}

Because of very few if any study on the effectiveness of biofeedback on the hand function and also controversies

Copyright (C) 2015, Zahedan University of Medical Sciences. This is an open-access article distributed under the terms of the Creative Commons Attribution-NonCommercial 4.0 International License (http://creativecommons.org/licenses/by-nc/4.0/) which permits copy and redistribute the material just in noncommercial usages, provided the original work is properly cited. 
in the previous results, the effectiveness of applying biofeedback therapy with occupational therapy exercises was investigated on recovery of hand function and ADL performances in patients with stroke.

\section{Patients and Methods}

In this randomized control trial study the effects of biofeedback therapy in addition to current occupational therapy exercises were studied on 24 stroke patients ( 9 males and 15 females) in one setting; Rehabilitation Center of Tabasom (Tehran, Iran). Participants were selected based on inclusion criteria such as:1-stroke diagnosis by neurologist, 2- scoring 22 and more in mini mental state examination (MMSE), 3- recognized as having score 2 and more in modified Ashworth test of spasticity, 4- absence of accompanying disorders such as seizure, psychological disorders, hearing or visual problem, or orthopedic disorders in upper extremities, 5- at least three months passed from incidence of stroke, 6- interested in participating in the study and 7- not suffering from hemianopia, Wernicke aphasia and global aphasia. This study and research was approved by "University of Social Welfare and Rehabilitation ethical committee". Informed consents were obtained prior to experiment and contents were comprehended and signed by patients or their legal representative.

All participants were provided with the information sheet and ensured that their participation in the research is voluntary and they are able to withdraw from the study in every stage of the process. Following their consent data were collected in the participant's convenient time and day. All people with stroke who provided consent to the study were included in the study. Subjects were blinded to the purpose of the study. There were five tools for collecting data. A questionnaire was used within which data on age, sex, right or left dominance, effected side, post-stroke duration, and the duration of receiving rehabilitation services were collected.

Folstein's mini-mental state examination (MMSE) with 6 subscales for orientation, registration, attention, calculation, recall, and language and praxis tests was used to estimate the patients' cognitive ability to participate in biofeedback therapy [20]. The modified Ashworth scale was used to measure the severity of spasticity in effected hand [21-24]. This scale has been designed to rating spasticity in different muscles and its spectrum rates are from zero (no increase in tonicity) to 4 (rigidity in flexion and extension). Then, the active range of motion (ROM) in upper limbs' joints including elbow, wrist and matacarpophalangeal were measured by goniometry. The extension ROM in elbow was measured in supine position. Because measuring of ROM in elbow starts from 150 degree full flexion and reaches zero degree, the full extension, therefore the angle of extension in elbow was subtracted from 150 to show a positive trend during increase in ROM. The ranges of motion in the wrist and finger were measured in a sagittal plane.
The ROM in the wrist was from zero to 70 degree full extension and in the finger was 90 degree in full extension.

Finally, the Barthel index (BI) was used to asses daily function status and independency in 10 categories of activities including bowel, bladder, grooming, toilet use, feeding, transfer, mobility, dressing, steps, and bathing. All assessments were repeated after the intervention period [25].

Participants were randomly assigned in the experimental or control groups. Participants in both groups received current occupational therapy including muscle stretching, positioning, facilitating normal patterns of movement, facilitator and inhibitory techniques, reflex inhibitory patterns, facilitating higher level reflexes and muscle tone normalization. Participants in experimental group received an additional biofeedback therapy for 10 minutes; altogether for 45 minutes each session. Intervention duration included three sessions a week for three months (altogether 36 sessions).

In biofeedback therapy, after stabilizing hand on the table with a hand-rest, electrodes were set on the bulk of wrist extensor muscles and lateral epicondyle of humerus, patients sat in front of monitor and watched the diagram of muscular contraction. By adjusting the threshold, if the patient could produce an activity in the extensor muscles above the threshold, music broadcasted from the machine. Therefore, he/she could receive appropriate feedback about contraction in the targeted muscle either in visual or auditory signals. The biofeedback tool in this research was Procomp Infiniti 5 channel model, made in USA.

The collected data from the two groups were analyzed using SPSS-20. Descriptive statistics were used for quantitative and qualitative data, and the statistical test was Kolmogorov-Smirnov that used to evaluate normal distribution of data. Equality of variables between the two groups was compared before intervention using independent t-test for quantitative and $\chi^{2}$ tests for qualitative variables. Statistical variance analysis for repeated measures (repeated measure ANOVA) was used to study the changes in test scores in each group during consequent assessments and then the mean scores of each test during sequential testing were compared in each group separately using paired t-test $(\mathrm{P}<0.01)$.

\section{Results}

As seen in the Table 1, from 24 participants (15 females and 9 males), 8 females and 4 males were assigned in experimental group and the rest ( 7 females and 5 males) in the control group. Only 2 subjects were left handed (both in experimental group) and the rest were right handed. Thirteen subjects were affected in the left side (right brain hemisphere) and 11 subjects were affected in right side of the body. From left side affected subjects, 6 subjects were assigned in experimental group and 7 subjects in the con- 
trol and from right side affected subjects, 6 patients were in the experimental group and the rest in the control group. According to the spasticity evaluation using modified Ashworth scale, 4 patients in experimental group, were rated as 2 score and 8 subjects as 3 score before intervention. In the control group 3 subjects have 2 and 9 subjects had scores 3 in modified Ashworth before intervention. After intervention, in experimental group 8 subjects had 2 and in control group 4 subjects were rated as 2 and the rest were rated as having scores 3 in modified Ashworth scales. The mean ROM of elbow in experimental group was 32.5 degree before intervention which increased to 82.1 degree after intervention, (approximately 50 degree increase in ROM), while mean increase in ROM in control group was reaching to 41.67 degree (post intervention) from 17.5 degree (pre-intervention) that is about 24 degree increase in mean).

In both groups, intervention (either occupational therapy or occupational therapy with biofeedback) resulted in increase in ROM in elbow, wrist and finger joints which are shown in the Table 2.

The mean ROM of wrist in experimental group was 13.75 degree before intervention which reached to 60.83 degree after intervention, while wrist Rom in control group increased from 11.67 to 43.92 degree.

Mean increase in the finger ROM in the experimental group was 32.91 degree, from 11.67 degree to 44.58 degree after intervention but in control group it was 7.92 degree, from 5.83 to 13.75 degree.
Post intervention assessment showed an increase in activities of daily living performances, the Barthel index score from 62.75 to 73.08 in experimental group and from 60.08 to 63.5 in control group. That is occupational therapy accompanying with biofeedback lead to more than 10 scores in Barthel index while occupational therapy alone has only 3.4 scores increase in Barthel index. The mean of changes in the elbow ROM after intervention were $49.6 \pm 36.02$ degree and $24.17 \pm 28.47$ degree in experimental and control groups, respectively. Using covariance analysis these data were analyzed. Biofeedback therapy caused a significant increase in elbow ROM of the patients with stroke $(\mathrm{P}=0.001)$. The mean increases in the wrist ROM in the experimental and control groups were $60.83 \pm 15.79$ degree and 43.92 \pm 20.12 degree respectively. Covariance analysis of data showed a significant increase in the wrist ROM of experimental group $(\mathrm{P}=0.003)$. Also the mean increases of finger ROM were $44.58 \pm 23.88$ degree and $13.75 \pm 27.48$ degree for the experimental and control groups, respectively. Using covariance analysis, mean ROM of finger after intervention were analyzed which showed a significant effectiveness of biofeedback intervention on finger ROM $(P=0.001)$. Furthermore, mean scores in the Barthel index score for the experimental and control groups after intervention were $73.08 \pm 13.64$ and $63.50 \pm 9.99$ Raw score, respectively. Using covariance analysis, patients' scores in Barthel index were analyzed after intervention, which results indicated the effectiveness of the biofeedback therapy on the activities of daily living performances $(\mathrm{P}=0.001)$.

Table 1. Characteristics of the Stroke Patients ${ }^{\mathrm{a}, \mathrm{b}}$

\begin{tabular}{lcccccccccc}
\hline \multirow{2}{*}{ Treatment Group } & \multicolumn{2}{c}{ Gender } & \multicolumn{2}{c}{ Hand Dominant } & Affected side & $\begin{array}{c}\text { Age, } \mathbf{y} \text { (Mean } \pm \text { SD }) \\
\text { Stroke, mo }\end{array}$ & $\begin{array}{c}\text { Time since } \\
\text { Seceiving Rehab } \\
\text { Services, mo }\end{array}$ \\
\cline { 2 - 11 } & $\mathbf{F}$ & $\mathbf{M}$ & $\mathbf{L}$ & $\mathbf{R}$ & $\mathbf{L}$ & $\mathbf{R}$ & & & \\
\hline Experimental group $^{c}$ & $9(75)$ & $3(25)$ & $2(16.7)$ & $10(83.3)$ & $6(50)$ & $6(50)$ & $57.1 \pm 2.9$ & 18.25 & 8.25 \\
Control group $^{c}$ & $6(50)$ & $6(50)$ & $0(0)$ & $12(100)$ & $7(58.3)$ & $5(41.7)$ & $52.4 \pm 4.3$ & 2.25 & 8.41 \\
Total & $15(62.5)$ & $9(37.5)$ & $2(8.3)$ & $22(91.7)$ & $13(54.2)$ & $11(45.8)$ & $54.7 \pm 2.6$ & 19.75 & 8.33 \\
\hline
\end{tabular}

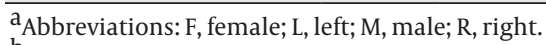

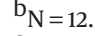

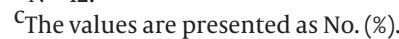

\begin{tabular}{|c|c|c|c|c|}
\hline Joint ROM, degree & Elbow & Wrist & Finger & Barthel Index \\
\hline Exp (pretest) & $18.6 \pm 32.5$ & $7.4 \pm 13.75$ & $11.9 \pm 11.67$ & $10.76 \pm 62.75$ \\
\hline $\operatorname{Exp}$ (posttest) & $36 \pm 82.1$ & $15.7 \pm 60.83$ & $23.8 \pm 44.58$ & $13.64 \pm 73.08$ \\
\hline Control (pretest) & $18.1 \pm 17.5$ & $6.8 \pm 11.67$ & $13.79 \pm 5.83$ & $6.34 \pm 60.08$ \\
\hline Control (posttest) & $28.4 \pm 41.67$ & $20.1 \pm 43.92$ & $27.4 \pm 13.75$ & $9.99 \pm 63.5$ \\
\hline
\end{tabular}

a Abbreviations: Exp, experimental group; ROM, range of motion.

$\mathrm{b}_{\text {The values are presented as mean } \pm \text { SD. }}$ 


\section{Discussion}

According to the results of our study, using biofeedback training in addition to current occupational therapy exercises in patients with stroke leaded to significant decrease in upper extremity spasticity. Also, significant increases were observed in range of motion of elbow, wrist and fingers joints in experimental group (who received biofeedback and occupational therapy) in comparison with control group (who received only occupational therapy exercises). Furthermore, increase in the activities of daily living performance was remarkably more in experimental group when compared to control group. These finding demonstrated the effectiveness of biofeedback therapy when applied in accompanying with occupational therapy exercises.

Hemiplegia is one of the most consequences of stroke [26] which leads to disorder in activities of daily living performances and decrease in quality of life [27]. Hence rehabilitation team focuses on acquiring the maximum of independence in activities of daily living performances of stroke survivors [28].

Many different and alternative techniques are used by occupational therapist including biofeedback therapy to reach the mentioned goals. This technique causes the activation of voluntary control on single muscles in patients with sensory motor disorders. In addition, increase in range of motion and decrease in spasticity can increase in activities of daily living performances (if accompanied by active participation). Active participation in ADL necessitates the activity of different gross and fine muscles. While some studies have shown the improvement of gross muscles after biofeedback therapy $[15,29]$, there was few if any study on the effectiveness of biofeedback on muscles involved in fine motor activities [7].

In present research data analysis showed a positive effect of biofeedback on the range of motion in elbow, wrist and finger in patients with stroke. Furthermore, increase in the ROM is coupled with improvement and facility in activities of daily living performances, as can be seen in patients' scores in Barthel index. Although, considering Barthel index scores showed an improvement in activities of daily living performances in both the experimental and control groups, but this recovery in experimental group were significantly more than that of control group. Data support the effectiveness of biofeedback therapy on the activities of daily living performances in the experimental group. While data on goniometry indicated effectiveness of occupational therapy on the range of motion in control group, but differences between the two groups were significant. In addition, while participants in the both groups showed decrease in spasticity (Ashworth score) but in the experimental group many more patients showed a decrease in Asworth scores from 3 to 2. In accordance with these findings, the effectiveness of electromyography biofeedback in functional recovery of hand in hemiplegic patients has been reported $[16,30$,
31]. In the mentioned research [16] biofeedback therapy and placebo biofeedback have been compared which has showed better recovery in active ROM of wrist in subjects received biofeedback when compared to control group (receiving placebo). In that research, griping a glass which is a complicated hand function was assessed. This function has showed an improvement in both groups and there was not a significant difference between them. According to the author's report, this could be due to psychological role of placebo biofeedback which can act as a motive for activities of daily living performances. Hence more studies are needed to shed light on these dark angles. Furthermore, it has been reported [11] that application of electromyography biofeedback on upper extremities in hemiplegic stroke survivors caused decrease in hyperactivity of biceps brachii, wrist and finger flexors, thenar eminence and flexor synergist at all. In addition this intervention has lead to optimized neuromuscular function and recovery of function by following the treatment protocol.

In the present study, the subjects who showed a decrease in spasticity after biofeedback therapy were much more than these subjects in control group. Accordingly, in a systematic review in 2007, researchers using electromyography biofeedback in upper extremities of stroke patients were reviewed [32]. One of the researches has shown the positive effects of electromyography biofeedback in accompanying with rehabilitation programs on the ROM of shoulder. The two other studies have shown the effectiveness of these treatments on functional ability of upper extremities. Therefore, considering the present results and previous studies, it could be concluded that, using biofeedback technique in accompanying with routine occupational therapy can effectively improve the ROM and reduce spasticity in the upper limbs of stroke survivors.

Stroke survivors suffer from disability in activities of daily living performances which consequently leads to decrease in their quality of life. Considering the present findings, the biofeedback therapy is a potent treatment modality in increasing the ROM in upper limb and improves the activities of daily living performances which can lead to increase in independency and quality of life. These factors are among the most key points in rehabilitation of the patients with stroke.

\section{Acknowledgments}

The article is derived from a master thesis by Tahereh Haji-Ahmad, supervised by Hojjat Allah Haghgoo and approved by Ethical Committee of the University of Social Welfare and Rehabilitation Sciences (code: 400-239). The authors hereby acknowledge the participants, their family and the Tabasom center staffs for their helpful assistances.

\section{Footnotes}

Authors' Contribution:All authors had equal role in design, work, statistical analysis and manuscript writing. 
Funding/Support:This paper had been done by personal expenses.

\section{References}

1. Steultjens EM, Dekker J, Bouter LM, van de Nes JC, Cup EH, van den Ende $\mathrm{CH}$. Occupational therapy for stroke patients: a systematic review. Stroke. 2003;34(3):676-87. doi: 10.1161/01. STR.0000057576.77308.30. [PubMed:12624291]

2. Maffetone P. Manual Biofeedback. JAltern Med Res. 2009;1(3):221-32.

3. Delarque A, Viton JM. [Project for an international teaching programme for physical rehabilitation medicine trainees, coordinated by the French Association of Academic Physiatrists (Cofemer), in cooperation with the other French national PRM associations (Sofemer, Syfmer and Fedmer) and the journal annals of PRM]. Ann Phys Rehabil Med. 2009;52(10):685-6. doi: 10.1016/j. rehab.2009.11.004. [PubMed:19995662]

4. Prigatano G, Pliskin N. Clinical neuropsychology and cost outcome research: A beginning. United Kingdom: Psychology Press; 2002. p. 112.

5. Klotz T, Borges HC, Monteiro VC, Chamlian TR, Masiero D. Physiotherapy treatment in hemiplegic shoulder pain in stroke patients-Literature Review. Acta Fisiatr. 2006;13(1):12-6.

6. Jette DU, Latham NK, Smout RJ, Gassaway J, Slavin MD, Horn SD. Physical therapy interventions for patients with stroke in inpatient rehabilitation facilities. Phys Ther. 2005;85(3):238-48. [PubMed: 15733048]

7. Armagan O, Tascioglu F, Oner C. Electromyographic biofeedback in the treatment of the hemiplegic hand: a placebo-controlled study. Am J Phys Med Rehabil. 2003;82(11):856-61. doi: 10.1097/01. PHM.0000091984.72486.E0. [PubMed:14566153]

8. Nakayama H, Jorgensen HS, Raaschou HO, Olsen TS. Recovery of upper extremity function in stroke patients: the Copenhagen Stroke Study. Arch Phys Med Rehabil. 1994;75(4):394-8. [PubMed: 8172497]

9. Weil A. Biofeedback. 2014. Available from: http://www.drweil. com/drw/u/ART0 0466/ Biofeedback-Dr-Weil-Wellness-Therapies.html.

10. AAOS. Complementary therapies: Biofeedback. American Academy of Orthopaedic Surgeons; 2007. Available from: http://orthoinfo. aaos.org/topic.cfm?topic=A00201.

11. Wolf SL, Binder-MacLeod SA. Electromyographic biofeedback applications to the hemiplegic patient. Changes in upper extremity neuromuscular and functional status. Phys Ther. 1983;63(9):1393403. [PubMed: 6611660]

12. Hammond DC. Neurofeedback treatment for traumatic brain Injury. 2012. Available from: http:/|www.internationalbrain.org/articles/ neurofeedback-treatment-for-traumatic-brain-injury|.

13. Spillar C. Miraculous recovery from traumatic brain injury with neurofeedback therapy. 2011. Available from: http://thedubinclinic. com/traumatic-brain-injury-treatment-los-angeles/.

14. Lourencao MI, Battistella LR, de Brito CM, Tsukimoto GR, Miyazak $\mathrm{MH}$. Effect of biofeedback accompanying occupational therapy and functional electrical stimulation in hemiplegic patients. Int Rehabil Res. 2008;31(1):33-41. doi:10.1097/MRR.0b013e3282f4524c. [PubMed: 18277202]

15. Hershko E, Tauber C, Carmeli E. Biofeedback versus physiotherapy in patients with partial weight-bearing. Am J Orthop (Belle Mead NJ). 2008;37(5):E92-6. [PubMed: 18587509]

16. Dogan-Aslan M, Nakipoglu-Yuzer GF, Dogan A, Karabay I, Ozgir gin N. The effect of electromyographic biofeedback treatment in improving upper extremity functioning of patients with hemiplegic stroke. J Stroke Cerebrovasc Dis. 2012;21(3):187-92. doi: 10.1016/j.jstrokecerebrovasdis.2010.06.006. [PubMed: 20880720]

17. van Dijk H, Jannink MJ, Hermens HJ. Effect of augmented feedback on motor function of the affected upper extremity in rehabilitation patients: a systematic review of randomized controlled trials. J Rehabil Med. 2005;37(4):202-11. doi: 10.1080/16501970510030165. [PubMed: 16024475]

18. Hemmen B, Seelen HA. Effects of movement imagery and electromyography-triggered feedback on arm hand function in stroke patients in the subacute phase. Clin Rehabil. 2007;21(7):587-94. doi:10.1177/0269215507075502. [PubMed:17702700]

19. Bate PJ, Matyas TA. Negative transfer of training following brief practice of elbow tracking movements with electromyographic feedback from spastic antagonists. Arch Phys Med Rehabil. 1992;73(11):1050-8. [PubMed: 1444771]

20. Folstein MF, Folstein SE, McHugh PR. "Mini-mental state". A practical method for grading the cognitive state of patients for the clinician. J Psychiatr Res. 1975;12(3):189-98. [PubMed:1202204]

21. Ashworth B. Preliminary trial of carisoprodol in multiple sclerosis. Practitioner. 1964;192:540-2. [PubMed:14143329]

22. Bohannon RW, Smith MB. Interrater reliability of a modified Ashworth scale of muscle spasticity. Phys Ther. 1987;67(2):206-7. [PubMed:3809245]

23. Nuyens G, De Weerdt W, Ketelaer P, Feys H, De Wolf L, Hantson L, et al. Inter-rater reliability of the Ashworth scale in multiple sclerosis. Clin Rehabil. 1994;8(4):286-92. doi: 10.1177/026921559400800403.

24. Brashear A, Zafonte R, Corcoran M, Galvez-Jimenez N, Gracies JM, Gordon MF, et al. Inter- and intrarater reliability of the Ashworth Scale and the Disability Assessment Scale in patients with upper-limb poststroke spasticity. Arch Phys Med Rehabil. 2002;83(10):1349-54. [PubMed: 12370866]

25. Mahoney FI, Barthel DW. Functional evaluation: the barthel index. Md State Med J.1965;14:61-5. [PubMed:14258950]

26. Altschuler EL, Wisdom SB, Stone L, Foster C, Galasko D, Llewellyn DM, et al. Rehabilitation of hemiparesis after stroke with a mirror. Lancet. 1999;353(9169):2035-6. [PubMed:10376620]

27. Haghgoo HA, Pazuki ES, Hosseini AS, Rassafiani M. Depression, activities of daily living and quality of life in patients with stroke. J Neurol Sci. 2013;328(1-2):87-91. doi: 10.1016/j.jns.2013.02.027. [PubMed: 23522526]

28. Corr S, Bayer A. Occupational therapy for stroke patients after hospital discharge - a randomized controlled trial. Clin Rehabil. 1995;9(4):291-6. doi:10.1177/026921559500900403.

29. Basmajian JV, Gowland CA, Finlayson MA, Hall AL, Swanson LR, Stratford PW, et al. Stroke treatment: comparison of integrated behavioral-physical therapy vs traditional physical therapy programs. Arch Phys Med Rehabil. 1987;68(5 Pt 1):267-72. [PubMed: 3579530]

30. Turczynski BE, Hartje W, Sturm W. Electromyographic feedback treatment of chronic hemiparesis: an attempt to quantify treatment effects. Arch Phys Med Rehabil. 1984;65(9):526-8. [PubMed: 6477085]

31. Balliet R, Levy B, Blood KM. Upper extremity sensory feedback therapy in chronic cerebrovascular accident patients with impaired expressive aphasia and auditory comprehension. Arch Phys Med Rehabil.1986;67(5):304-10. [PubMed: 3518658]

32. Woodford H, Price C. EMG biofeedback for the recovery of motor function after stroke. Cochrane Database Syst Rev. 2007;(2):e2204 doi:10.1002/14651858.CD004585.pub2. [PubMed:17443550] 